\title{
MVDC for Enhanced Utility Scale Distribution Power Delivery and Control
}

\author{
Lewis Hunter \\ University of Strathclyde, Scotland University of Strathclyde, Scotland \\ lewis.hunter.100@strath.ac.uk
}

\author{
Adria Junyent Ferre, \\ Imperial College, London \\ adria.junyent-ferre@imperial.ac.uk
}

\author{
Stephen Finney \\ University of Strathclyde, Scotland \\ stephen.finney@strath.ac.uk
}

\begin{abstract}
The electrification of heat and transport along with significant increases in distributed energy resources pose challenges for distribution network operators (DNOs) as they evolve into distribution system operators (DSOs). Issues may include capacity constraints, voltage excursions, lower supply security and reduced power quality. A method of addressing these matters whilst unlocking capacity is therefore required.

This paper will outline the case for the selective interconnection of grid supply points and primary substations via fully controllable power electronic links. This interconnection would form the basis of a 'power levelling' network to help alleviate the above concerns as an alternative to a conventional 'more copper' reinforcement strategy. Power flows for a conventional network will be benchmarked before assessing the potential capacity release created by delivering energy from multiple substations via controllable interconnection.

Medium voltage direct current (MVDC) networks (operating in the range of $5-50 \mathrm{kV}$ ) represent a candidate technology for the proposed interconnection. The paper reviews current technology readiness level, international learning and relevant knowledge from other power sectors.
\end{abstract}

\section{Index Terms-MVDC, Active Distribution, DC Power Systems}

\section{INTRODUCTION}

$\mathrm{T}$ HE simplicity and flexibility of ac power networks has made them the preferred choice for transmission and distribution operators for the past century due to the passive nature of components and the ease at which voltages can be transformed. Since the mid-1960s, the role of dc transfers has increased primarily for long distance cross border energy trading and the transfer of energy from remote sources in the form of High Voltage Direct Current (HVDC) [1]. For long distance transmission HVDC transfers have a number of advantages over conventional ac solutions;

- Elimination of charging current and reduced conduction loss

- Connection of independent ac synchronous grids

- Greater power densities can be achieved using dc than ac for a given voltage level.

- Fully controllable power flows

- Creates a natural "firewall" between systems so that disturbances on one system do not impact significantly upon the other

Whilst dc is present in transmission and to a degree in generation industries, with fully-rated back-to-back converters for wind applications and dc solar collection networks, there is, as yet, no dc used within utility scale distribution networks other than for substation battery backup schemes for re-configuration under outage conditions.

The rapid shift towards a low carbon economy via increased electrification of heat [2] [3] and transport [4]-[6] coinciding with the increase of distributed energy resource [7] [8] has and will put further pressure upon distribution networks and their associated operators. Distribution networks which were originally designed for centralised generation dispatch delivered through transmission infrastructure now have much more multi-megawatt distributed generation (DG) connected upon them due to the widespread availability of renewable resource, lowering of technology price and governmental policy.

This paper will provide an overview of the electrical design of a typical UK distribution network, based on a Scottish example. Present day management strategies intended to alleviate network congestion will be summarised. Using existing network data, a distribution network with a large installed capacity of distributed generation will be benchmarked to highlight the poor use of assets and the pinch-point congestion that often occur with such, largely passive networks. Using the software analysis platform DIgSILENT PowerFactory 15, the network will be re-examined to determine whether constraints can be alleviated by converting a single line to a controlled medium voltage direct current (MVDC) link. The simulation will be extended to examine whether introducing a second dc link (a soft normally open point, or SNOP) across a substation's normally open bus coupler can further increase network capacity without adversely impacting fault level.

\section{Distribution NETWORK DESIGN AND CONTRACTUAL ARRANGEMENTS [9] [10]}

In Scotland there are three common distribution and supply voltages, 33, 11, and $0.4 \mathrm{kV}$ with limited legacy $6.6 \mathrm{kV}$ sections. The transmission operator supplies $33 \mathrm{kV}$ to the distribution network operator at a grid supply point (GSP) via transformation from transmission voltages of $400 \mathrm{kV}, 275 \mathrm{kV}$ or 132 $\mathrm{kV}$. A number of $33 \mathrm{kV}$ circuits then connect to primary substations located throughout the served area. Primary transformers convert $33 \mathrm{kV}$ to $11 \mathrm{kV}$ with typical unit ratings of $5-24$ MVA. Transformers are banked to ensure redundancy in the event of a transformer failure or planned outage. Primary substations have partial interconnection with adjacent primaries allowing load to be served under a planned or forced outage. Reconfiguration of networks is achieved by altering the state of normally open and normally closed points either manually or via remote telecontrol. Fig. 1 illustrates a typical section of network. 
An overly interconnected system may allow fault level to increase beyond the operational limits of switchgear. Operating above switchgear rating means that current may fail to be interrupted successfully on actuation of circuit breaking devices. Protection schemes may not issue trip signals (or may react relatively slowly) if the fault level is too low. Maximum design fault levels are 1,000 MVA and 250 MVA for 33 and $11 \mathrm{kV}$ systems respectively in the UK [11].

For modelling purposes, the downstream $11 \mathrm{kV}$ and $0.4 \mathrm{kV}$ network will be modelled as lumped $11 \mathrm{kV}$ real and reactive power injections or demands.

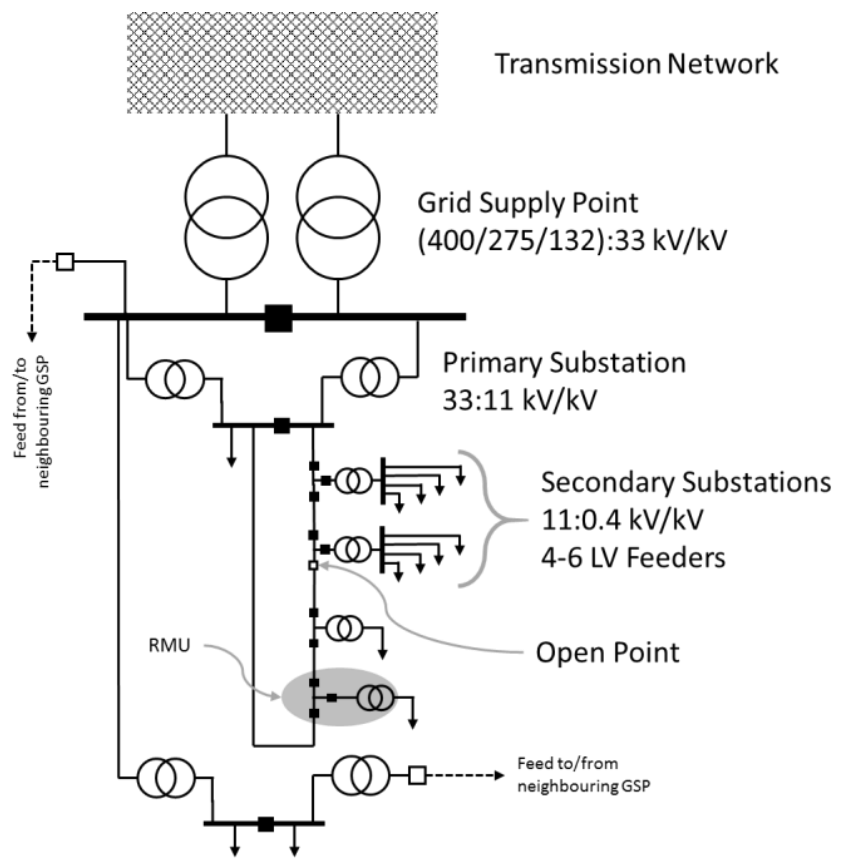

Fig. 1. Simple single-line distribution network topology.

The past two decades have seen a large increase in distributed (generally renewable) generators connecting to the distribution network [12]. Whilst firm capacity contracts can be offered, and are preferred, it is common for a non-firm first in, last off (FILO) approach to be adopted by DNOs to manage power injections from distributed generators. This approach prevents incumbent generators being adversely affected by new generation.

SP Energy Networks (SPEN) (along with other DNOs) offer a number of 'alternative' connection agreements where a standard non-firm contract cannot be offered [13].

- ANM (Active Networks Management)

- $\quad$ ELD (Export Limit Determined)

- DSM (Demand Side Management)

- TM (Temperature Monitored).

Whilst these contracts allow the connection of generation which otherwise would not be allowed to connect under a firm agreement there is undoubtedly a requirement for more capacity to be unleashed on these networks to allow growth of renewable technologies.

Due to the passive nature of the network once one line reaches its continuous rating there is very little capacity for more generators to connect. The impedance 'map' of networks also means that some conductors may end up very lightly loaded whilst others are reaching thermal or voltage limits as will be observed in the following sections. If flows could be managed more effectively there is opportunity to exploit existing infrastructure more fully, rather than constraining valuable renewable resource, without adversely affecting fault level as would be the case with traditional topologies.

\section{CASE STUDY}

\section{A. Test network overview}

For the purposes of this case study a section of network from south west Scotland will be considered (Fig. 2) with system data primarily extracted from SPEN's long term development statement [9]. This network has significant levels of distributed renewable generation connected to various nodes upon the network. The network consists of two GSPs with the capacity of embedded generation behind the Coylton GSP exceeding the transformer's firm rating with applications to connect further generation requested. Kilmarnock South GSP has significantly lower levels of generation connected but with a greater firm capacity than its counterpart (Table I)

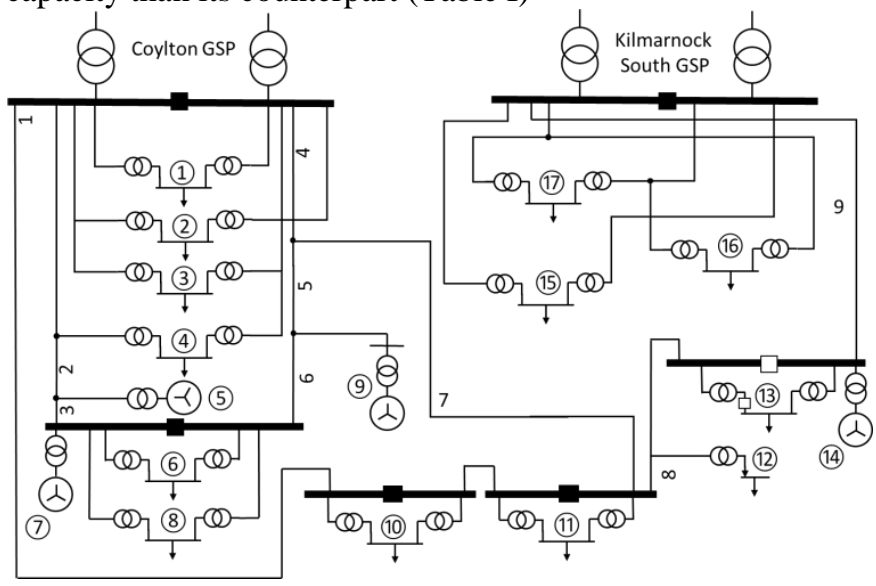

Fig. 2. Case study network consisting of thirteen load buses and four large scale windfarms.

Thirteen primary substations connect across the network. Loads are modelled as fixed real and reactive demands at a voltage of 1 p.u as outlined in Table II.

TABLE I

DISTRIBUTED GENERATION CONNECTED AND CONTRACTED TO CONNECT FOR ASSOCIATED GSP (VALUES IN MVA) [14]

\begin{tabular}{|c|c|c|c|c|}
\hline GSP & $\begin{array}{c}\text { Firm } \\
\text { Capacity }\end{array}$ & Connected & Contracted & $\begin{array}{c}\text { Net } \\
\text { increase }\end{array}$ \\
\hline Coylton & 60 & 72.35 & 91.60 & 19.25 \\
\hline $\begin{array}{c}\text { Kilmarnock } \\
\text { South }\end{array}$ & 120 & 16.10 & 30.40 & 14.3 \\
\hline
\end{tabular}


TABLE II

SUBSTATION NAME, FIRM CAPACITY, MIN/MAX LOADING AND POWER FACTOR ASSOCIATED WITH FIG. 2 [9] [14]

\begin{tabular}{|c|c|c|c|c|c|}
\hline$I D$ & Name & $\begin{array}{c}\text { Firm } \\
\text { Capacity } \\
\text { MVA }\end{array}$ & $\begin{array}{l}P \max \\
M V A\end{array}$ & $\begin{array}{l}P \min \\
M V A\end{array}$ & $P F$ \\
\hline GSP1 & Coylton & 60 & 43.49 & 10.87 & \\
\hline GSP2 & Kilmarnock South & 120 & 33.47 & 8.37 & \\
\hline (1) & Lethanhill & 10 & 4.08 & 1.02 & 0.98 \\
\hline (2) & Killoch & 2 & 12.6 & 3.15 & 0.68 \\
\hline (3) & Cronberry & 5 & 2.32 & 0.88 & 0.96 \\
\hline (4) & Cumnock & 24 & 9.55 & 2.39 & 0.93 \\
\hline (5) $*$ & Harehill WF & 13 & & & \\
\hline (6) & New Cumnock & 5 & 2.78 & 2.39 & 0.76 \\
\hline (7) $*$ & Harehill WF (ext) & 33 & & & \\
\hline (8) & Fauldhead & 10 & 4.74 & 1.19 & 0.99 \\
\hline (9) $*$ & Gallowrig WF & 21.6 & & & \\
\hline (10) & Drumley & 10 & 6.7 & 1.67 & 1 \\
\hline (11) & Mauchline & 10 & 5.7 & 1.44 & 0.99 \\
\hline (12) & Darvel & 10 & 1.9 & 0.47 & 1 \\
\hline (13) & Newmilns & 24 & 5.86 & 1.46 & 0.99 \\
\hline (14) $*$ & Bankend Rig WF & 14.3 & & & \\
\hline (15) & Riverside & 40 & 4.54 & 1.14 & 1 \\
\hline (16) & Monkton & 21 & 13.35 & 3.34 & 0.99 \\
\hline (17) & Kilmarnock & 24 & 15.14 & 3.79 & 0.99 \\
\hline
\end{tabular}

To carry out load flow studies on the network DIgSILENT PowerFactory 15 was employed primarily due to the ease of incorporating controllable links.

On-load tap changers on the primary transformers were set to target a voltage of $1( \pm 0.03)$ p.u. at $11 \mathrm{kV}$ busbars as specified in ER P2/6 and ER P2/8 for simulations [15] [16]. Generation units were set such that the voltage at the point of common coupling (PCC) to the network were also maintained at 1 p.u.

As daily load profiles for individual substations were unobtainable, it was assumed that there was no diversity between loadings and thus maxima (and minima) demands were modelled as being fully correlated; Initial load flows were carried out upon the network. $33 \mathrm{kV}$ bus voltages were all regulated to a voltage tolerance of $3 \%$ from nominal as required. A sample of simulation results are shown in Table III for selected lines.

TABLE III

KEY LINE LOADING FOR BASE NETWORK UNDER MAXIMUM AND MINIMUM LOAD

\begin{tabular}{|c|c|c|c|c|}
\hline \multirow{2}{*}{ Line } & \multirow{2}{*}{$\begin{array}{l}\text { Rating } \\
(\boldsymbol{M V A})\end{array}$} & \multirow{2}{*}{$\begin{array}{c}\text { Distance } \\
(\mathrm{km})\end{array}$} & \multicolumn{2}{|c|}{ Loading (\%) } \\
\cline { 4 - 5 } & & Max Demand & Min Demand \\
\hline 1 & 20.86 & 8.01 & 42.2 & 37.2 \\
\hline 2 & 38.81 & 8.48 & 60.3 & 60.3 \\
\hline 3 & 41.2 & 0.01 & 25.7 & 26.6 \\
\hline 4 & 38.81 & 6.29 & 70.4 & 82.9 \\
\hline 5 & 29.43 & 13.68 & 131.9 & 142.7 \\
\hline 6 & 20.86 & 0.025 & 75.8 & 91.8 \\
\hline 7 & 20.86 & 6.25 & 59.2 & 47.4 \\
\hline 8 & 24.63 & 12.56 & 8 & 1.9 \\
\hline 9 & 20.86 & 0.21 & 40.4 & 59.3 \\
\hline
\end{tabular}

The $13.68 \mathrm{~km}$ line 5 is the only recorded overload on the system at $131.9 \%$ of its rated capacity under maximum load conditions. This overload rises by 2.5 MVA to $142.7 \%$ when network demands are at their minimum due to the power produced by distributed generation not being absorbed locally to the same extent. The overload is partly due to the comparatively low impedance of this branch section when compared to neighbouring paths.

While existing non-firm contracting mechanisms (as outlined in Section II) would manage the identified line overload, if curtailment is too great and occurs too frequently, then any prospective generators wishing to connect may deem the situation not worthy of investment. There is a case to be made that power flows must be managed more actively at distribution level to allow renewable targets to be met.

\section{B. Introduction of controlled MVDC links}

In looking for a MVDC solution to the overload of line 5, it was converted to a symmetric monopole link operating at \pm 27 $\mathrm{kV}$ (Fig. 3). The motivation behind this conversion was to limit the power passing through line 5 to its rated capacity. Line resistance and inductance details were otherwise unchanged. The converter connected nearest the generator at bus 9 was set to P-Q control where both active and reactive power flows can be fully controlled. The remote end of the circuit was set to Vdc-Q control thus maintaining ac bus voltage to 1 p.u. and the dc potential to nominal.

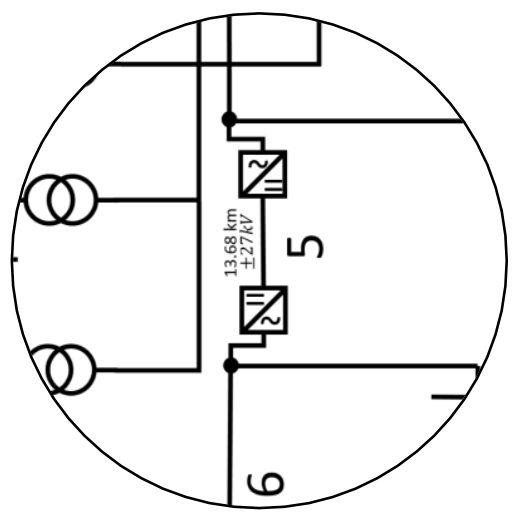

Fig. 3. Embedded dc link replacing existing line 5.

Simulations were run for both minimum and maximum demand scenarios. With the embedded dc link exporting $25 \mathrm{MVA}$ towards Coylton GSP, lines now remain within rated thermal capacity while voltages are within tolerance for the maximum demand scenario

At minimum demand and with the dc link operating at full capacity, line 2 recorded a $39.3 \%$ overload essentially transferring the overload from line 5 to line 2 .

A back-to-back converter, rated at 20.8 MVA was then connected across the $33 \mathrm{kV}$ normally open bus coupler (commonly referred to as a soft normally open point; SNOP [17]) at bus 13 (Fig. 4) to alleviate the minimum load, maximum generation congestion identified on line 2. A pair of load flows calculations were run for both maximum and minimum demand with embedded link transferring 25 MVA and SNOP transferring 11 MW for maximum system loading and 9 MW for minimum loading. The introduction of the SNOP combined with the embedded dc link allow all distributed resource to connect under 
minimum and maximum demand while operating within continuous line ratings and voltage limits. Percentage loading figures for the four outlined studies are presented in Table IV. Switching losses for each converter were assumed to be fixed at $1 \%$ of the link power transfer.

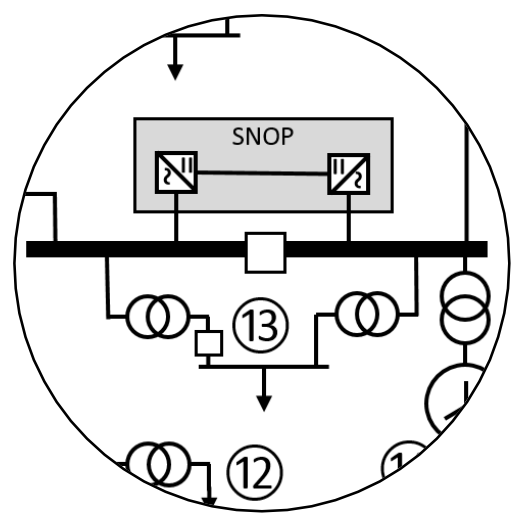

Fig. 4. SNOP virtually connecting Coylton GSP with Kilmarnock South GSP at $33 \mathrm{kV}$.

TABLE IV

RESULTS: LINE LOADING OF NETWORK AFTER MVDC CONVERSATION OF LINE 5 AND CLOSING THE NORMALLY OPEN POINT AT BUS 13 VIA A POWER ELECTRONIC BACK TO BACK CONVERTER

\begin{tabular}{|c|c|c|c|c|c|}
\hline \multirow{2}{*}{ Line } & \multirow{2}{*}{$\begin{array}{l}\text { Rating } \\
(\boldsymbol{M V A})\end{array}$} & \multicolumn{4}{|c|}{ Loading (\%) } \\
\cline { 3 - 6 } & & $\begin{array}{c}\text { Max } \\
\text { Demand }\end{array}$ & $\begin{array}{c}\text { Min } \\
\text { Demand }\end{array}$ & $\begin{array}{c}\text { Max } \\
\text { Demand }\end{array}$ & $\begin{array}{c}\text { Min } \\
\text { Demand }\end{array}$ \\
\hline 1 & 20.86 & 24.1 & 20.3 & 37.5 & 21.5 \\
\hline 2 & 38.81 & 91.6 & 139.3 & 91.6 & 92.4 \\
\hline 3 & 41.2 & 53.3 & 98.2 & 53.3 & 54.4 \\
\hline 4 & 38.81 & 34.8 & 55.0 & 17.3 & 29 \\
\hline 5 & 29.43 & 84.3 & 99 & 84.3 & 84.3 \\
\hline 6 & 20.86 & 22.6 & 42.2 & 22.6 & 22.4 \\
\hline 7 & 20.86 & 54.9 & 36.3 & 89.7 & 66.4 \\
\hline 8 & 24.63 & 8.2 & 1.9 & 64.4 & 44.2 \\
\hline 9 & 20.86 & 40.4 & 59.3 & 88.0 & 97.7 \\
\hline
\end{tabular}

C. Assumptions and discussion of MVDC modelling

In running simulations, the aim has been to support the maximum amount of distributed energy resources on the network without either overloading assets or constraining generation. Security of supply requirements have not been considered within the network.

Conductor impedance was modelled as a lumped element based upon RL/km. As there are many long lines within the network (maximum for this network being $35 \mathrm{~km}$ ) a more realistic $\pi$ or distributed element model could be used.

For simulation purposes it was assumed that line ratings remain the same under a dc conversion. In three wire schemes the direct conversion to a two wire dc yields a similar theoretical maximum power rating as ac assuming that using the ground as a return path is not permitted. In four wire cable distribution the power through a conductor can be increased by a factor of between 2.2 and 2.6 (depending on dc arrangement) over conventional three phase ac [18]. In two wire symmetrical monopole operation a conductor is effectively left unused other than to provide an earth path. The question remains open as to whether this third conductor could be more optimally used such as in the three wire bipolar topology proposed in [19].

\section{Facilitating contracted increase in renewable generation}

Analysis was carried out to investigate how the network could be modified to accommodate the additional generation seeking to connect (as described in Table I). A 20 MVA generator was connected at the junction between key lines 4,5 and 7 while a 15 MVA set was connected upon the primary side of busbar 11. Running at minimum demand, load flows were conducted for the case with no dc link and for the case of two controlled links as previously carried out. Selected line loading results are presented in Table V.

TABLE V

RESULTS: LINE LOADING OF BASE NETWORK AND ENHANCED DC NETWORK UNDER MINIMUM SYSTEM LOAD

\begin{tabular}{|c|c|c|c|}
\hline \multirow{2}{*}{ Line } & \multirow{2}{*}{$\begin{array}{l}\text { Rating } \\
(\boldsymbol{M V A})\end{array}$} & \multicolumn{2}{|c|}{$\begin{array}{c}\text { Loading (\%) } \\
\text { Minimum Demand }\end{array}$} \\
\cline { 3 - 4 } & & Base & DC Enhanced \\
\hline 1 & 20.86 & 53.7 & 44.6 \\
\hline 2 & 38.81 & 64.6 & 92.4 \\
\hline 3 & 41.2 & 30.3 & 54.4 \\
\hline 4 & 38.81 & 118.3 & 95.6 \\
\hline 5 & 29.43 & 137.5 & 84.3 \\
\hline 6 & 20.86 & 83 & 22.4 \\
\hline 7 & 20.86 & 65.9 & 32.6 \\
\hline 8 & 24.63 & 1.9 & 41.1 \\
\hline 9 & 20.86 & 124.2 & 81.4 \\
\hline
\end{tabular}

While some lines are approaching their continuous thermal rating, the introduction of controlled MVDC link has allowed firm connection of 122 MVA of distributed generation on a network which could not support the presently installed 88.5 MVA representing a capacity release of more than 33.5 MVA.

\section{E. Summary}

Existing distribution networks are under pressure due to increased embedded generation and demand patterns that are changing and increasing due to the electrification of transport and heating. The above case study of part of the SPEN network highlights the congestion that is now typical in rural parts of Scotland. Power flow analysis using DIgSILENT PowerFactory 15 has shown that the local assets are stressed in places yet underutilised elsewhere, suggesting that rebalancing and rerouting is required, something that is challenging using conventional ac solutions. It has been shown that dc technologies can be effective in alleviating problems - in this case, conversion of one line to dc and use of a SNOP to rebalance power flows has the potential to reduce congestion and to make better use of existing line assets. The analysis has focussed on keeping within thermal limits and in that context results are encouraging. Power quality and security factors have not yet been addressed and neither have the relative costs compared to conventional ac reinforcement. An important consideration is also the availability and maturity of the relevant dc technologies, a topic addressed in the next section. 


\section{MVDC TECHNOLOGY READINESS DISCUSSION}

\section{A. Related Applications and Adaption}

MVDC faces similar challenges to HVDC in the sense that semiconductor devices must withstand voltages that are not readily handled by single devices however a simple down scaling of HVDC is unlikely to yield the optimal solution as priorities for cost, volume, reliably and functionality are different. The properties for MVDC converters for grid applications reside between MV machine drives (used within wind turbines, traction, mining etc. generally between $2-14 \mathrm{kV}$ rating) and HVDC operating at hundreds of $\mathrm{kV}$ [1]. Although the power ratings of MV machine drives (typically 1-80 MVA) are similar to that which an MVDC network solution will take, the voltage capability of such converters needs to be increased to reduce resistive losses [20] . Knowledge from HVDC will be key to developing a suitable converter solution for an MV system.

$33 \mathrm{kV}$ and $11 \mathrm{kV}$ networks should be secure for one forced outage at all times under guidelines set out within P2/6 [15]. If $\mathrm{dc}$ were to play a greater role within utility distribution methods for maintaining equipment would undoubtedly be required.

\section{B. Other Considerations}

With space at a premium, (a suburban primary transformer site may be limited to $900 \mathrm{~m}^{2}$ ) a power electronics solution must be packaged appropriately such that volume and footprint are minimised whilst maintainability is preserved. Cooling systems also need to be considered in the design of such a network solution to regulate the heat accumulation associated with losses of semiconductor devices. Audible noise from two and three level converters trialled in distribution networks within the UK have been noted in previous trials [21].

MVDC has been proposed and evaluated for a multi-megawatt university campus electrification in RWTH-Aachen, Germany [22], defence applications and propulsion systems [23]. Research into the prospect of deploying MVDC collection networks for offshore wind applications have also been considered in detail [24].

\section{Protection}

Protection, particularly for multi-terminal overhead systems, needs careful consideration. Voltage source converters (VSC) are increasingly moving towards MMC (Modular Multilevel Converter) solutions for network applications due to their reduced harmonic when compared to two and three level VSC solutions. Whilst full bridge converters are fault blocking, they have twice the losses when compared to half bridge MMC. Furthermore conventional circuit breaking methodologies are unlikely to yield satisfactory performance. For multi-terminal VSC HVDC a maximum interruption time of $5 \mathrm{~ms}$ has been floated by numerous authors and companies as in [25]. While the protection requirement for an MVDC scheme is likely to be less onerous in reaction time than an HVDC deployment, in a similar way that fault clearance times at distribution level are generally longer than transmission clearance times to allow a suitable grading, it still needs further investigation as to allow a full multi-terminal arrangement to be achieved. Protection of point to point links is generally achieved through the blocking of device gate signals and tripping on the ac side network then using dc disconnectors thus avoiding the need for expensive and large dc breakers.

\section{ANGLEDC - MVDC TECHNOLOGY TRIAL}

Various UK governmental initiatives such as the Low Carbon Network Fund (LCNF), Network Innovation Allowance (NIA) and Network Innovation Competition (NIC) have been in place since 2010 with the aim of encouraging and stimulating innovation amongst network operators and thus cost savings to bill payers within the UK.

SPEN have proposed the interconnection between two areas of their north Wales licence area which have high DG penetration with significant load and generation growth predicted with the $33 \mathrm{kV}$ network already identified as operating near its design limits. The project, entitled AngleDC, is funded under the NIC scheme and is operational from 2016-2019 with total project budget of $£ 14.8$ million [26]. The reinforcement will take the form of a MVDC link operating at $\pm 27 \mathrm{kV}$ through existing repurposed $33 \mathrm{kV}$ cable and a small section of overhead line (allowing transient faults to be examined). The scheme rating is 30 MVA. SPEN believe this is the world's first example of an embedded dc link to be used within a distribution network. Project aims for AngleDC are outlined below; many of which were demonstrated through the case study presented previously.

- Achieve full control of active power at both converter stations

- Optimise wider network voltages

- Reduce losses (20\% being claimed resulting in an annual saving of $£ 630 \mathrm{k}$ )

- Defer conductor reinforcement by more fully using existing underutilised conductors (30.5 MW of network capacity to be released)

- Prevent overload of existing assets by using thermal loading rather than conventional passive thermal limit approach.

- Move MVDC from TRL (technology readiness level) 56 to $7-8$

\section{FURTHER WORK}

Different network license areas may have very different constructions; some may be predominantly overhead, underground or a mixture of the two. Overhead schemes are susceptible to non-permanent short term faults caused by animals and lightening etc. Methods of managing these faults have not been considered for this paper but will need attention to enable MVDC as a viable means of interconnection. The fault characteristics between ac and dc system interactions must also be more fully understood.

Although time variant data could not be obtained for the purposes of this exercise, it is intended that these simulations will in future help further inform whether network storage connected directly upon the dc network would provide an effective means of serving load and enabling more distributed energy resource. 


\section{CONCLUSION}

This paper aimed to set out the case for interconnection and consider the benefits of actively manging line loading and power flows rather than a conventional passive system. Design of present day distribution networks and the challenges faced by DNOs (and by DSOs in the future) in managing the increase of load and generation upon their system have been presented. Current constraint management methods through non-firm connection contacts have been outlined.

Through DIgSILENT PowerFactory 15 simulations it has been demonstrated that the passive nature of networks means that an overload in one area can hinder the connection of further DG. Load flow studies provide evidence that increasing controllability of distribution networks, using MVDC, allows for greater adoption of low carbon technologies.

Consideration of other industries using similar power and voltage ratings of power electronics have been discussed. Connection of the first distribution network trial of an embedded MVDC links is currently underway in Wales, UK. From project documentation it is clear that the link, as well as realising the primary aim of controlling power flows, will provide secondary benefits of improved voltage profiles.

\section{ACKNOWLEDGMENTS}

This work has been supported through the EPSRC Centre for Doctoral Training in Future Power Networks and Smart Grids (EP/L015471/1).

\section{REFERENCES}

[1] IEEE/PED Transmission and Distribution Committee, "Existing HVDC Projects Listing," IEEE HVDC and FACTS Subcommittee, 2013. [Online]. Available: https://goo.gl/DyJCef. [Accessed 05 May 2017].

[2] "Ground Source Heat Pump Association," [Online]. Available: http://www.gshp.org.uk/. [Accessed 18 May 2017].

[3] "RHI deployment data: March 2017 and Q1 2017," Department for Business, Energy \& Industrial Strategy, UK Government, 20 April 2017. [Online]. Available: https://goo.gl/eEoziB. [Accessed 28 April 2017].

[4] Department of Transport, UK Government, "Statistics at DFT," 4 May 2017. [Online]. Available: https://goo.gl/H82odL.

[5] "Plug-in car, motorcycle and van grants - Eligibility, Department of Transport, UK Government," 09 May 2017. [Online]. Available: https://goo.gl/S1pQWR.

[6] Zap Map, "Charging Point Statistics 2017," 08 May 2017. [Online]. Available: www.zap-map.com/statistics. [Accessed 08 May 2017].

[7] "Solar photovoltaics deployment," 27 April 2017. [Online]. Available: https://goo.gl/K0jy34. [Accessed 11 May 2017].
[8] National Grid, "Future Energy Scenarios," 2017. [Online]. Available: http://fes.nationalgrid.com/. [Accessed 24 April 2016].

[9] SP Energy Networks, "Long Term Development Statement," 2016.

[10] E. Lakervi and E. Holmes, Electricity Distribution Network Design, London: The Institution of Engineering and Technology, 2008.

[11] SP Energy Networks, "Calculation of System Fault Levels - ESDD-02006 Issue 2," 2008.

[12] K. L. Anaya and M. G. Pollitt, "Integrating Distributed Generation: Regulation - EPRG-WP-1423,” December 2014. [Online]. Available: http://www.eprg.group.cam.ac.uk/. [Accessed 10 May 2016].

[13] SP Energy Networks, "Alternative DG Connection Offers," [Online]. Available: https://goo.gl/d81qmS. [Accessed 04 May 2017].

[14] SP Energy Networks, "Getting Connected - SP Distribution Heat Maps," [Online]. Available: https://goo.gl/pdHBpG. [Accessed 14 May 2017].

[15] The Engineering Council, "Engineering Recomendation P2/6 Electricity Distribution Network Planning," London, 2006.

[16] The Engineering Council, "Engineering Recommendation P2/8 Planning limits for voltage fluctuations," London, 1989.

[17] J. M. Bloemink and T. C. Green, "Increasing distributed generation penetration using soft normally-open points," in Power and Energy Society General Meeting, IEEE, Providence, RI, USA, 2010.

[18] P. Salonen, T. Kaipia, P. Nuutinen, P. Peltoniemi and J. Partanen, “An LVDC Distribution System Concept," in Nordic Workshop on Power and Industrial Electronics, Helsinki , 2008.

[19] A. Elserougi, A. M. Massoud, A. S. Abdel-Khalik and S. Ahmed, "Three-wire bipolar HVDC line using an existing single-circuit HV AC line for integrating renewable energy sources in multiterminal DC networks," IET Renewable Power Generation, vol. 10, no. 3, p. 370, 2015.

[20] "MV7000," GE Power Conversion, 2017. [Online]. Available: https://goo.gl/NGfUIt. [Accessed 22 May 2017].

[21] UKPN, "LV Distribution Networks Characteristics for Power Electronics Devices," in Hubnet - Power Electronics in Distribution Networks, London, 2016.

[22] E.On Energy Research Centre, "Preparation of a Medium-Voltage DC Grid Demonstration Project," RWTH Aachen University, Aachen, Germany, 2012.

[23] Z. Jin, G. Sulligoi, R. Cuzner, L. Meng, J. C. Vasquez and J. M. Guerrero, "Next-Generation Shipboard DC Power System," IEEE Electrification Magazine, vol. 4, no. 2, pp. 45-57, 2016.

[24] M. Carmeli, F. Castelli-Dezza, D. Rosati, G. Marchegiani and M. Mauri, "MVDC Connection of Offshore Wind Farms to the Transmission System," International Symposium on Power Electronics, Electric Drives, Automation and Motion, p. 1201, 2010.

[25] ABB, "The Hybrid HVDC Breaker," November 2012. [Online]. Available: https://goo.gl/qMP9b4. [Accessed 26 May 2016].

[26] SP Energy Networks, "Angle-DC 2015 Electricity Network Innovation Competition,” 2015. [Online]. Available: https://goo.gl/k5Zswl. [Accessed March 2017]. 